E3S Web of Conferences 1, 21005 (2013)

DOI: $10.1051 / \mathrm{e} 3$ sconf/20130121005

(c) Owned by the authors, published by EDP Sciences, 2013

\title{
Concentrations of heavy metals in hair as indicators of environmental pollution
}

\author{
$\underline{\text { A. } \text { Baran }^{1} \text { and J. Wieczorek }}{ }^{2}$ \\ ${ }^{1}$ Department of Agricultural and Environmental Chemistry, University of Agriculture in Krakow, al. A. Mickiewicza 21, \\ 31-120 Krakow, POLAND, Agnieszka.Baran@ur.krakow.pl \\ ${ }^{2}$ Department of Agricultural and Environmental Chemistry, University of Agriculture in Krakow, al. A. Mickiewicza 21, \\ 31-120 Krakow, POLAND, rrwieczo@cyf-kr.edu.pl
}

\begin{abstract}
Over 80 hair samples were collected from $38 \%$ males and $62 \%$ females in Krakow, Poland. The hairs sampled for the analysis were washed in the water-acetone-water arrangement (three times). Subsequently the hair samples were wet mineralized in a closed system $\mathrm{HNO}_{3}: \mathrm{H}_{2} \mathrm{O}_{2}$ (6:1) in a microwave furnace. Concentrations of $\mathrm{Zn}, \mathrm{Pb}$ and $\mathrm{Cd}$ were assessed by means of ICP-OES method. Obtained results of analysis of heavy metal concentrations in the hair of tested population of Krakow inhabitants evidence environmental hazard (beside professional hazard)We observed that the hair of females showed higher levels of zinc and cadmium. Hair analysis allows for an assessment of the natural environment contamination, which is particularly important for the research on populations inhabiting areas with different degree of pollution.
\end{abstract}

Key words: hair, heavy metals, environment pollution, biomarkers

\section{Introduction}

Hair analysis finds applications for various purposes, among others in forensic toxicology or clinical pathology, to determine the level of nutrition but also for biological monitoring of professional and environmental exposure to heavy metals. According to numerous authors, assessment of heavy metal concentrations in hair of specified populations, particularly children may serve as a means to detect the areas excessively polluted by individual metals and for comparing amounts of pollutants in different environments. In many investigations hair analysis was an indicator of the environment pollution with heavy metals such as lead or cadmium. Currently chemical analysis of hair may be best used in ecological and epidemiological screening particularly as the first indicator of environment pollution with heavy metals. Many authors have emphasized that these studies are far more easier to conduct than blood or urine analysis. It is worth mentioning that hair has been selected by the World Health Organization (WHO) and Environment Protection Agency for an assessment of toxic metal influence on human organism (Srogi 2004).

The research will aim to determine the content of heavy metals $(\mathrm{Zn}, \mathrm{Pb}, \mathrm{Cd})$ in the hair of people (children, females and males) living in city area of Krakow. Analysis of hair from the citizens of Krakow will be an indicator of heavy metal pollution in their dwelling environment.

\section{Materials and Methods}

The research has covered 80 people who according to the conducted survey reveal a good state of health and have not been exposed to harmful agents (metals) due to profession they practise. A questionnaire given to all participants provided the following information: sex, age, home address, smoking, nutritional habits and occupational exposure to heavy metals. A whole length of a hair (not subjected to hairdresser's treatment), cut by the skin from 5 or 6 points of head and of a total mass of $1-1.5 \mathrm{~g}$ was sampled for the analysis. The hairs sampled for the analysis were washed in the water-acetone-water arrangement (three times). Subsequently the hair samples $(0.3 \mathrm{~g})$ were wet mineralized in a closed system $\mathrm{HNO}_{3}: \mathrm{H}_{2} \mathrm{O}_{2} \quad(6: 1)$ in a microwave furnace. Concentrations of $\mathrm{Zn}, \mathrm{Pb}$ and $\mathrm{Cd}$ were assessed by means of ICP-OES method. The method was controlled on a certified reference material NCSDC73357a (GSH-1a) Human Hair. Obtained results were verified statistically and average, standard deviation, variation coefficient, minimums and maximums, and dispersion of results were calculated. 
Table 1. Contents of zinc, lead and cadmium in the hair of people ( $\mathrm{mg} \cdot \mathrm{kg}^{-1}$ of dry matter)

\begin{tabular}{|c|c|c|c|c|c|c|}
\hline \multicolumn{2}{|c|}{ Metal } & Average & Standard deviation & Minimums & Maximums & Variation coefficient \% \\
\hline \multirow{4}{*}{$\mathrm{Zn}$} & Female & 260.86 & 218.29 & 75.82 & 1049.11 & 84 \\
\cline { 2 - 7 } & Male & 241.68 & 89.82 & 38.82 & 442.29 & 37 \\
\cline { 2 - 7 } & Generally & 253.45 & 179.38 & 38.82 & 1049.11 & 71 \\
\hline \multirow{4}{*}{$\mathrm{Pb}$} & Female & 2.46 & 1.35 & 0.08 & 7.17 & 55 \\
\cline { 2 - 7 } & Male & 3.04 & 2.63 & 0 & 14.36 & 86 \\
\cline { 2 - 7 } & Generally & 2.68 & 1.95 & 0 & 14.36 & 73 \\
\hline \multirow{3}{*}{$\mathrm{Cd}$} & Female & 0.19 & 0.18 & 0 & 2.8 & 95 \\
\cline { 2 - 7 } & Male & 0.09 & 0.08 & 0 & 0.35 & 89 \\
\cline { 2 - 7 } & Generally & 0.15 & 0.13 & 0 & 2.8 & 87 \\
\hline
\end{tabular}

\section{Results and Discussion}

Data on the concentrations of various metals in female and male scalp hair of the population of Krakow (industrial area) are given in Table I. Sex was the most important variable influencing the $\mathrm{Cd}, \mathrm{Zn}$ and $\mathrm{Pb}$ content in hair. However, several authors did not find significant differences between sexes (Wilhelm et al. 1994). In the present work, in female hair samples, $\mathrm{Zn}$ showed a maximum concentration of $1049.11 \mathrm{mg} \cdot \mathrm{kg}^{-1}$, followed by $\mathrm{Pb} 7.17 \mathrm{mg} \cdot \mathrm{kg}^{-1}$, while $\mathrm{Cd}$ was found at the $2.8 \mathrm{mg}$. $\mathrm{kg}^{-1}$ level (Tab. 1). Of all the metals analysed for males, the range of concentrations found for $\mathrm{Zn}$ was between 38.82 and $442.29 \mathrm{mg} \cdot \mathrm{kg}^{-1}$, followed by $\mathrm{Pb}$, between 0 and $14.49 \mathrm{mg} \cdot \mathrm{kg}^{-1}$ and $\mathrm{Cd}$ between 0 and $0.35 \mathrm{mg} \cdot \mathrm{kg}^{-1}$ (Tab. 1). The metal to metal correlation showed that for females and males a significant correlation coefficient $(r$ $>0.600$ ) was found between $\mathrm{Zn}$ and $\mathrm{Cd}$.

The observed spread in metal concentrations could be considered to arise from various factors, including racial, geographical, social, cultural and ethnic backgrounds, in addition to a whole multitude of variables such as environmental exposure, health conditions, food habits of individuals, their living conditions and environmental impacts [Wilhelm et al. 1994).

\section{Conclusion}

Obtained results of analysis of heavy metal concentrations in the hair of tested population of Krakow inhabitants evidence environmental hazard (beside professional hazard). Heavy metal content was diversified depending on the analyzed element and gender. Conducted analyses confirmed usefulness and necessity of conducting research basing on the use of sensitive biomarkers, such as hair. Hair analysis allows for an assessment of the natural environment contamination, which is particularly important for the research on populations inhabiting areas with different degree of pollution.

\section{References}

Srogi K. Heavy metals in human hair samples from Silesia Province: The influence of sex, age and smoking habit. Probl. Forensic Sci., 2004; LX: 727.

Wilhelm M., Lombeck I. Nesorge F. K., Cadmium, copper, lead and zinc concentrations in hair and toenail of young children and family members: a follow-up study, Sci. Total Environ., 1994; 35: 174 185. 